\title{
Nozzle Tip Device
}

National Cancer Institute

\section{Source}

National Cancer Institute. Nozzle Tip Device. NCI Thesaurus. Code C50325.

A device designed to form the end of a nozzle. 